\title{
Phosphoserine Aminotransferase1 Is Part of the Phosphorylated Pathways for Serine Biosynthesis and Essential for Light and Sugar-Dependent Growth Promotion
}

\author{
Sabine Wulfert and Stephan Krueger* \\ Biocenter - Botanical Institute II, University of Cologne, Cologne, Germany
}

OPEN ACCESS

Edited by:

Deyu Xie,

North Carolina State University,

United States

Reviewed by:

Leszek A. Kleczkowski,

Umeå University, Sweden

André O. Hudson,

Rochester Institute of Technology,

United States

*Correspondence:

Stephan Krueger

stephan.krueger@uni-koeln.de

Specialty section:

This article was submitted to

Plant Metabolism

and Chemodiversity,

a section of the journal

Frontiers in Plant Science

Received: 18 September 2018 Accepted: 05 November 2018

Published: 20 November 2018

Citation:

Wulfert S and Krueger S (2018) Phosphoserine Aminotransferase1 is Part of the Phosphorylated Pathways for Serine Biosynthesis and Essential for Light and Sugar-Dependent

Growth Promotion.

Front. Plant Sci. 9:1712. doi: 10.3389/fpls.2018.01712
The phosphorylated pathway of serine biosynthesis represents an important pathway in plants. The pathway consist of three reactions catalyzed by the phosphoglycerate dehydrogenase, the phosphoserine aminotransferase and the phosphoserine phosphatase, and the genes encoding for all enzymes of the pathway have been identified. Previously, the importance of the phosphoglycerate dehydrogenase and phosphoserine phosphatase for plant metabolism and development has been shown, but due to the lack of T-DNA insertion mutants, a physiological characterization of the phosphoserine aminotransferase is still missing. Hence, we generated silencing lines specifically down-regulated in the expression of the major PSAT1 gene. The morphological characterization of the obtained PSAT1-silenced lines revealed a strong inhibition of shoot and root growth. In addition, these lines are hypersensitive to the inhibition of the photorespiratory serine biosynthesis, when growing the plants at elevated $\mathrm{CO}_{2}$. Metabolic analysis of PSAT1-silenced lines, showed a strong accumulation of certain amino acids, most likely due to an enhanced ammonium assimilation. Furthermore, phenotypic analysis under low and high-light conditions and in the presence of sucrose revealed, that the phosphorylated pathway of serine biosynthesis is essential for light and sugar-dependent growth promotion in plants.

Keywords: serine biosynthesis, primary metabolism, photorespiration, amino acid metabolism, growth promotion, Arabidopsis thaliana

\section{INTRODUCTION}

Serine is an important intermediate in various metabolic pathways in plant metabolism, including photorespiration, the biosynthesis of phospholipids, the one-carbon metabolism and the synthesis of amino acids, such as glycine, methionine, cysteine, and tryptophan (Vance and Steenbergen, 2005; Rebeille et al., 2007; Krueger et al., 2009; Tzin and Galili, 2010). In yeast, serine is synthesized by two pathways, the phosphorylated pathway of serine biosynthesis (PPSB), and the gluconeogenic pathway (Pizer, 1963; Snell, 1984; Melcher and Entian, 1992; Achouri et al., 1997; Dey et al., 2005). 
In most other organisms, such as mammals, algae and bacteria, serine is mainly synthesized by the PPSB (Pizer, 1963; Snell, 1984; Melcher and Entian, 1992; Achouri et al., 1997; Dey et al., 2005).

In plants, the situation is more complicated since serine is synthesized by three different pathways, the photorespiration, the glycerate pathway and the PPSB (Ros et al., 2014).

The photorespiratory pathway starts with the synthesis of 2-phosphoglycolate by the oxygenase reaction of ribulose1,5-bisphosphate carboxylase/oxygenase. Via multiple reactions localized in chloroplasts and peroxisomes 2-phosphoglycolate is converted to glycine and subsequently to serine. More than $70 \%$ of the serine synthesized by the photorespiration is recycled by the serine glyoxylate aminotransferase reaction to feed back the carbon into the Calvin cycle and only $30 \%$ is used to satisfy the demand of serine for other cellular processes (Busch et al., 2018).

The biosynthesis of serine by the glycerate pathway represents the reverse sequence of reactions of the photorespiration, from 3-phosphoglycerate to serine (Figure 1; Kleczkowski and Givan, 1988). Although, the activity of all the enzymes involved in the glycerate pathway could be measured in plant extracts, the physiological relevance of the pathway is still not confirmed (Ros et al., 2014).

Within the PPSB serine is synthesized from 3phosphoglycerate and the pathway consists of three sequential reactions that are catalyzed by 3-phosphoglycerate dehydrogenase (PGDH), 3-phosphoserine aminotransferase (PSAT), and 3-phosphoserine phosphatase (PSP) enzymes (Ho and Saito, 2001). All enzymes of the PPSB are localized in plastids and most of the genes are dominantly expressed in heterotrophic tissue, except PGDH3, which is expressed only in leaves and PSP, which is expressed in both leaf and root tissue (Benstein et al., 2013).

The coexistence of three serine biosynthetic pathways in plants complicates the understanding of serine homeostasis in plants.

Photorespiratory serine biosynthesis is intimately associated with photosynthesis and therefore restricted to photosynthetic tissue. In the absence of photorespiration, serine is most likely synthesized either by the glycerate pathway or the PPSB.

The PPSB enzymes are encoded in plants by small gene families. The Arabidopsis genome contains three genes for the PGDH (At4g34200, PGDH1; At1g17745, PGDH2; At3g19480, PGDH3), two genes for the PSAT (At4g35630, PSAT1, and At2g17630, PSAT2) and one gene for the PSP (At1g18640). Deficiency in either the PGDH1, or the PSP gene causes embryo lethality and male sterility and plants with reduced activity of PGDH1 or PSP showed a strong inhibition of shoot and primary root growth (Benstein et al., 2013; Cascales-Minana et al., 2013). In addition, plants simultaneously inhibited in photorespiration and PPSB activity are completely arrested in growth (Benstein et al., 2013), indicating that these two pathways are of major importance for serine homeostasis whereby the glycerate pathway seems to play only a minor role in plants. It has been proposed that the PPSB is of increased relevance during the dark (Cascales-Minana et al., 2013), but there is substantial evidence that the PPSB is also essential in the light (Ho et al., 1998).

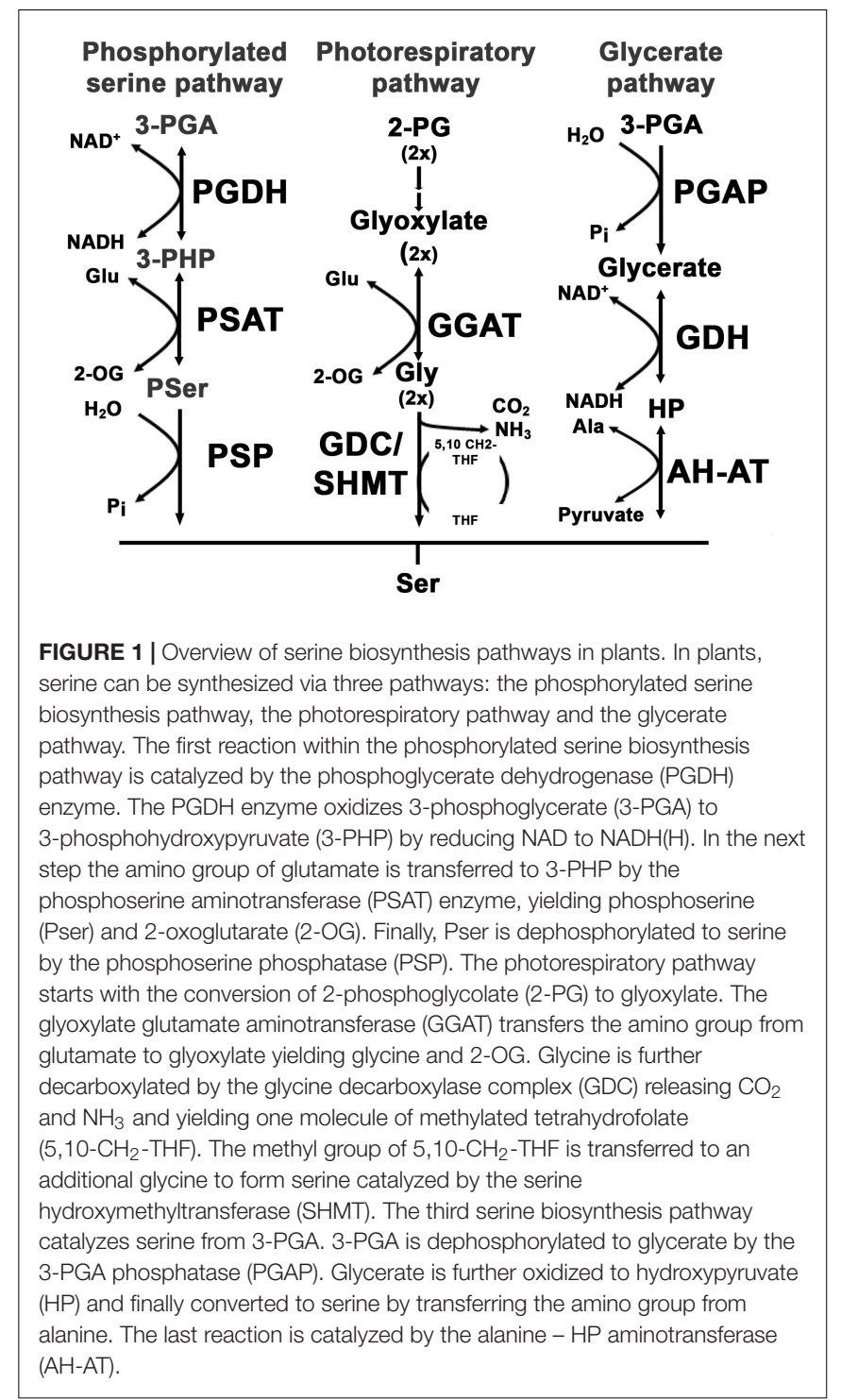

In contrast to the strong phenotype of $P G D H 1$ mutant plants, mutation in either $\mathrm{PGDH} 2$ or $\mathrm{PGDH} 3$ does not result in any obvious phenotype (Benstein et al., 2013; Toujani et al., 2013). Therefore, the role of these two genes in serine biosynthesis via the PPSB is still not known. In addition, due to the lack of T-DNA insertion mutants, it is still unclear whether the two genes, annotated as PSAT, encode for functional PSAT enzymes and whether these enzymes contribute to serine biosynthesis via the PPSB. The PSAT belongs to the group of aminotransferase enzymes. Aminotransferases catalyze the reversible transfer of amino groups from amino acids to oxoacids and are involved in many different reactions in plants (Mehta et al., 1993). The in vitro analysis of several aminotransferases revealed that some are highly substrate specific (Hirayama et al., 1998), whereas others are rather unspecific (Zhang et al., 2013). A prominent example for the broad substrate range of some aminotransferases is the serine: glyoxylate aminotransferase (AGT1) (Zhang et al., 2013). This enzyme catalyzes the transfer of amino groups 
from alanine, serine, glycine and asparagine to several different oxoacids in vitro. Overexpression of the AGT1 enzyme in plants alters significantly the content of serine, alanine and asparagine (Modde et al., 2017), indicating that this enzyme also catalyzes several reactions in vivo. Thus, the analysis of the in vivo function of aminotransferase enzymes is essential to understand their function in plants.

Database searches revealed that the two putative PSAT enzymes form a clearly isolated clade within the large group of annotated plant aminotransferases (Figure 2). In addition, these enzymes showed no homology to other proteins ${ }^{1}$, indicating that these two enzymes are the only PSAT proteins in Arabidopsis. To study the function of the putative PSAT genes in Arabidopsis, we analyzed their expression pattern, generated silencing lines to down-regulate the major expressed PSAT1 gene and functionally characterized these lines under various growth conditions.

\section{RESULTS}

\section{Identification and Expression Patterns of PSAT Genes in Arabidopsis thaliana}

Two genes, PSAT1 (At4g35630) and PSAT2 (At2g17630) with a high similarity to the SERC gene from Escherichia coli, the CCDS6659 gene from Homo sapiens and the YOR184W gene from Saccharomyces cerevisiae were identified in the Arabidopsis thaliana genome (Figure 2). Homologous PSAT genes were further identified in the genome of all sequenced green plants present in the Phytozome 12 database ${ }^{2}$. The number of PSAT isoforms present in the different plant genomes is rather diverse. Most of the plants contain two PSAT genes, whereas others contain only one PSAT isoform or up to five (Supplementary Figure 1). In Arabidopsis, the two PSAT isoforms contain a putative target peptide for localization into plastids (Figure 2A). The consensus prediction for plastid localization of both PSAT proteins is with a score of 26.2 for PSAT1 and 27.3 for PSAT2, fairly high, indicating that both proteins are plastid localized.

PSAT1 is the most expressed isoform and the expression of both genes is higher in root than in shoot tissue (Figure 3A). In order to study the tissue specific expression pattern of PSAT genes in more detail, Arabidopsis plants expressing the $\beta$-glucuronidase (GUS) reporter gene under the control of either PSAT1 or PSAT2 promoter were analyzed (Figure 3B). In 10 days old plants the activity of both PSAT gene promoters is high in the shoot apical meristem (SAM), the root apical meristem (RAM), in the vasculature of the hypocotyl and in the vasculature of roots, whereas the PSAT1 promoter is additionally active in the vasculature tissue of cotyledons and young leaves. In general, the expression pattern of both PSAT genes resembles rather the expression pattern of the $P G D H 1$ and $P G D H 2$ gene, with a higher expression in root than in shoot tissue, than the expression of the PSP gene. The gene encoding for the PSP is much weaker expressed than the other genes and the expression is similar in root and shoot tissue.

${ }^{1}$ http://aramemnon.uni-koeln.de

${ }^{2}$ https://phytozome.jgi.doe.gov/pz/portal.html

\section{Reduction of PSAT1 Gene Expression Severely Impairs Plant Growth}

The PSAT1 gene is the most expressed isoform in Arabidopsis thaliana and its expression is strongly correlated with the expression of the $P G D H 1^{3}$, which has been shown to be the major PGDH isoform in Arabidopsis (Benstein et al., 2013). This finding strongly suggest a role of PSAT1 in the PPSB. As no T-DNA insertion lines are available for the PSAT1 and PSAT2 genes $^{4}$, PSAT1-silenced lines (ts-psat1.1 and ts-psat1.2) were generated for functional characterization using a microRNAbased approach (Felippes et al., 2012). Plants harboring an empty vector construct were used as control and further referred to EV.

Overexpression of the artificial PSAT1-silencing construct in Arabidopsis leads to a significant reduction of PSAT1 expression, which subsequently results in a strong inhibition of growth (Figures 4A,B). In contrast, the expression of the second PSAT gene was unaltered in PSAT1-silenced plants (Figure 4B). When these plants were grown at standard light conditions $[100 \mu \mathrm{mol}$ (photons) $\mathrm{m}^{-2} \mathrm{~s}^{1}$ ] the leaf area and therefore the rosette diameter was much smaller compared to the shoot of the EV control plants (Figure 4A). But not only growth of the aerial part of PSAT1-silenced lines was impaired, also the growth rate of the primary root was significantly reduced from $0.1977 \mathrm{~mm} \mathrm{~h}^{-1}$ for EV control plants to $0.0295 \mathrm{~mm} \mathrm{~h}^{-1}$ and $0.0539 \mathrm{~mm} \mathrm{~h}^{-1}$ for ts-psat1.1 and ts-psat1.2 lines, respectively (Figures 5A,B).

To confirm that the growth phenotype observed for PSAT1-silenced plants is due to serine deficiency, plants were transferred from plates containing $1 / 2$ MS medium to plates additionally supplemented with $0.1 \mathrm{mM}$ serine, after germination. Determination of the primary root growth rate of plants grown on medium supplemented with serine revealed no significant difference between the EV control plants and ts-psat1.1 and ts-psat1.2 lines.

In addition, the primary root growth rate of plants transferred for 8 days from ambient to elevated $\mathrm{CO}_{2}$ was analyzed (Figures 5A,B). The primary root growth rate of $\mathrm{EV}$ control plants was significantly enhanced from $0.1977 \mathrm{~mm} \mathrm{~h}^{-1}$ at ambient $\mathrm{CO}_{2}$ to $0.3528 \mathrm{~mm} \mathrm{~h}^{-1}$ at elevated $\mathrm{CO}_{2}$ conditions. In contrast, the primary root growth rate of $t s$-psat 1.1 and $t s$ psat1.2 lines was reduced from 0.0295 and 0.0539 to 0.0138 and $0.0261 \mathrm{~mm} \mathrm{~h}^{-1}$, respectively (Figure 5B). The primary root growth rate of ts-psat1.1 and ts-psat1.2 lines was determined at the first 2 days after transferred to elevated $\mathrm{CO}_{2}$ only, as later growth of both lines was arrested (Figures 5A,B). In general, PSAT1-silenced plants gradually stop growth of the shoot and the root after transfer to elevated $\mathrm{CO}_{2}$.

\section{Knockdown of PSAT1 Alters Amino Acid Metabolism in Plants}

The PSAT enzyme catalyzes the transfer of the amino group of glutamate to 3-phosphohydroxypyruvate, yielding in 2oxoglutarate and 3-phosphoserine (Figure 1). Therefore, the phosphoserine pathway is intimately associated with glutamate

\footnotetext{
${ }^{3}$ http://atted.jp/

${ }^{4}$ http://signal.salk.edu/cgi-bin/tdnaexpress
} 


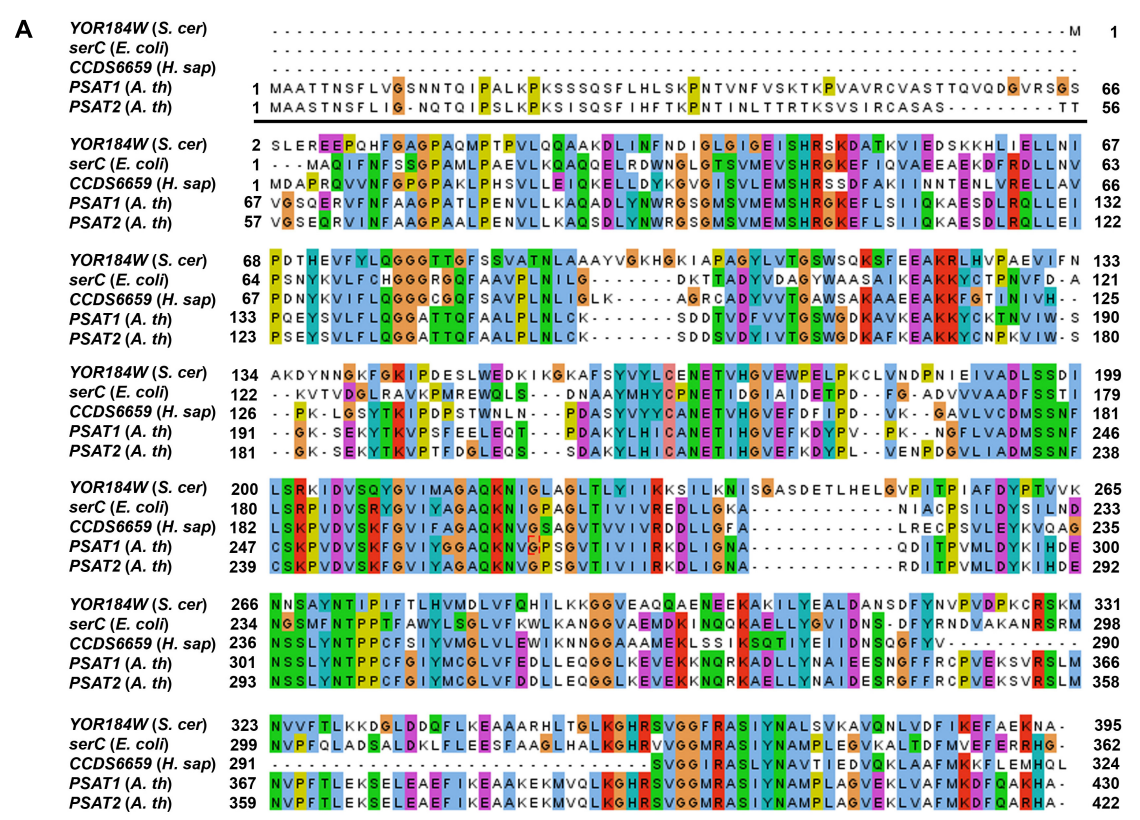

B

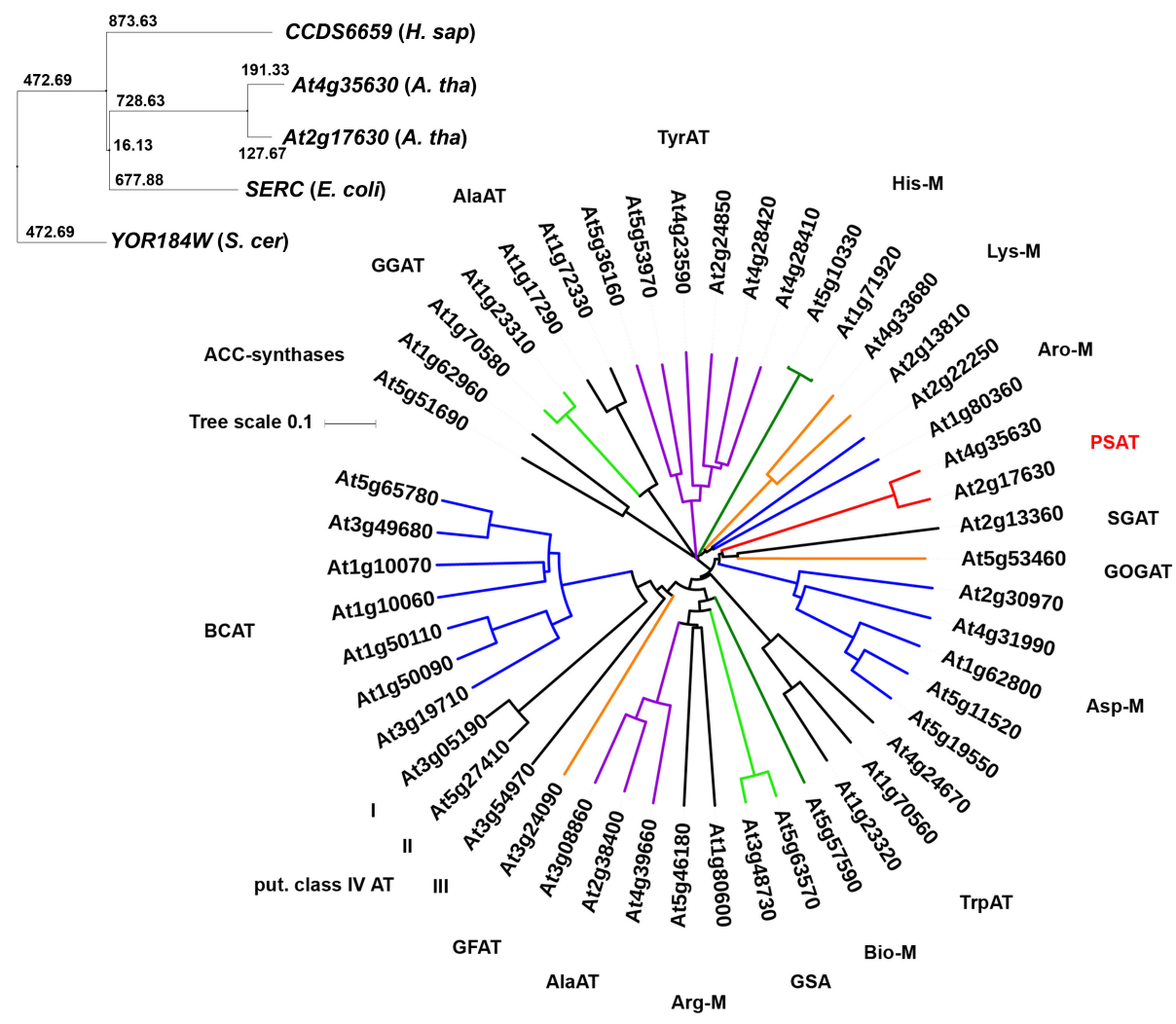

FIGURE 2 | Sequence comparison of PSAT proteins. Sequence comparison of PSAT proteins of Escherichia coli, Saccharomyces cerevisiae, Homo sapiens, and Arabidopsis thaliana (A,B). Phylogenetic tree of proteins annotated as aminotransferase enzymes in the ARAMEMNON database (Schwacke et al., 2003), release 8.1 (B). ACC, amino-cyclopropane-1-carboxylate)-synthases; GGAT, glutamate:glyoxylate aminotransferase; AlaAT, alanine aminotransferase; TyrAT, tyrosine aminotransferase; His-M, aminotransferases involved in histidine metabolism; Lys-M, aminotransferases involved in lysine metabolism; Aro-M, aminotransferases involved in biosynthesis of aromatic amino acids; PSAT, phosphoserine aminotransferase; SGAT, serine:glyoxylate aminotransferase; GOGAT, glutamate:oxoglutarate aminotransferase; Asp-M, aminotransferases involved in aspartate metabolism; TrpAT, tryptophan aminotransferase; Bio-M, aminotransferases involved in biotin metabolism; GSA, aminotransferases involved in chlorophyll biosynthesis; Arg-M, aminotransferases involved in arginine metabolism; GFAT, glutamate:fructose aminotransferase; BCAT, branched chain aminotransferases. 


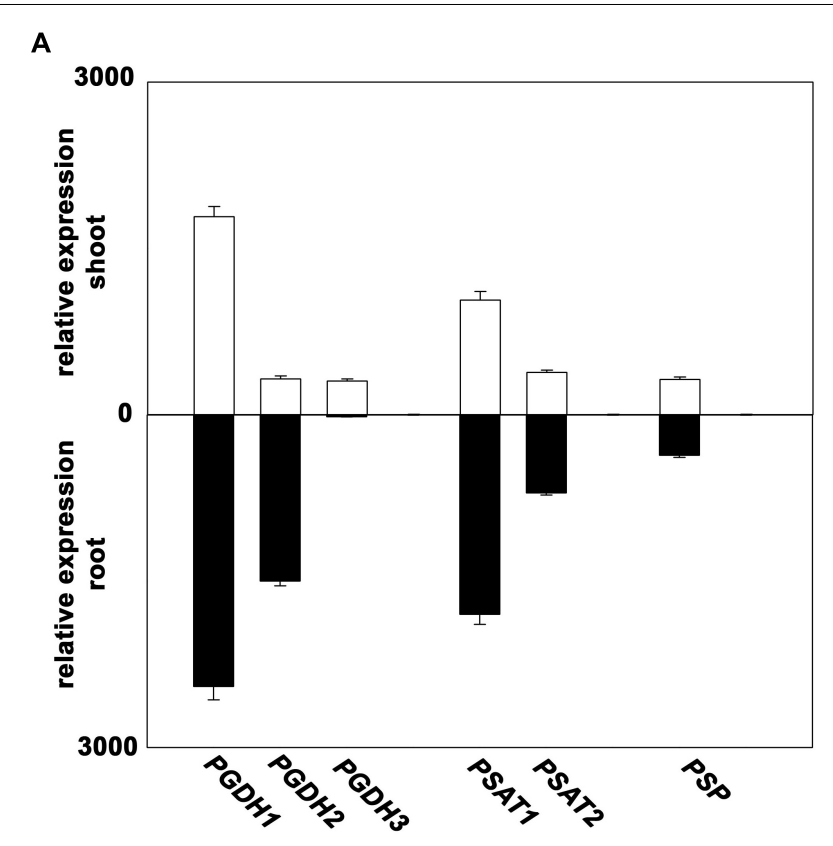

B

\section{PrOPSAT1:GUS}
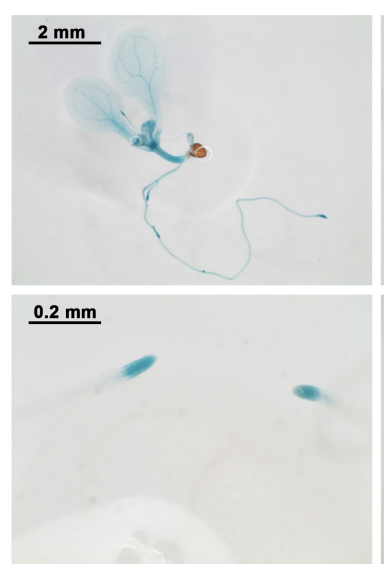

PrOPSAT2:GUS

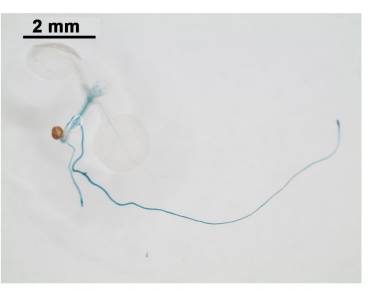

$\underline{0.5 \mathrm{~mm}}$
FIGURE 3 | Expression pattern of PPSB genes in Arabidopsis thaliana Expression level of PPSB genes in shoot and root tissue of Arabidopsis plants obtained from publicly available resources (http://bar.utoronto.ca/) (A). For analysis of the spatial distribution of PSAT1 and PSAT2 expression, plants expressing the GUS gene under the control of either the PSAT1 or PSAT2 promoter were analyzed (B)

metabolism in plants. To investigate the influence of PSAT1deficiency on amino acid metabolism, the content of free amino acids was quantified in shoot and root tissue of control and PSAT1-silenced plants.

The quantification of amino acids revealed no significant changes in the content of serine and glycine in root and shoot tissue in ts-psat1.1 and ts-psat1.2 lines in comparison to control plants (Figure 6). Similarly, the content of histidine, tyrosine, tryptophan, leucine, isoleucine and methionine was also not altered in PSAT1-silenced plants. However, the content of some
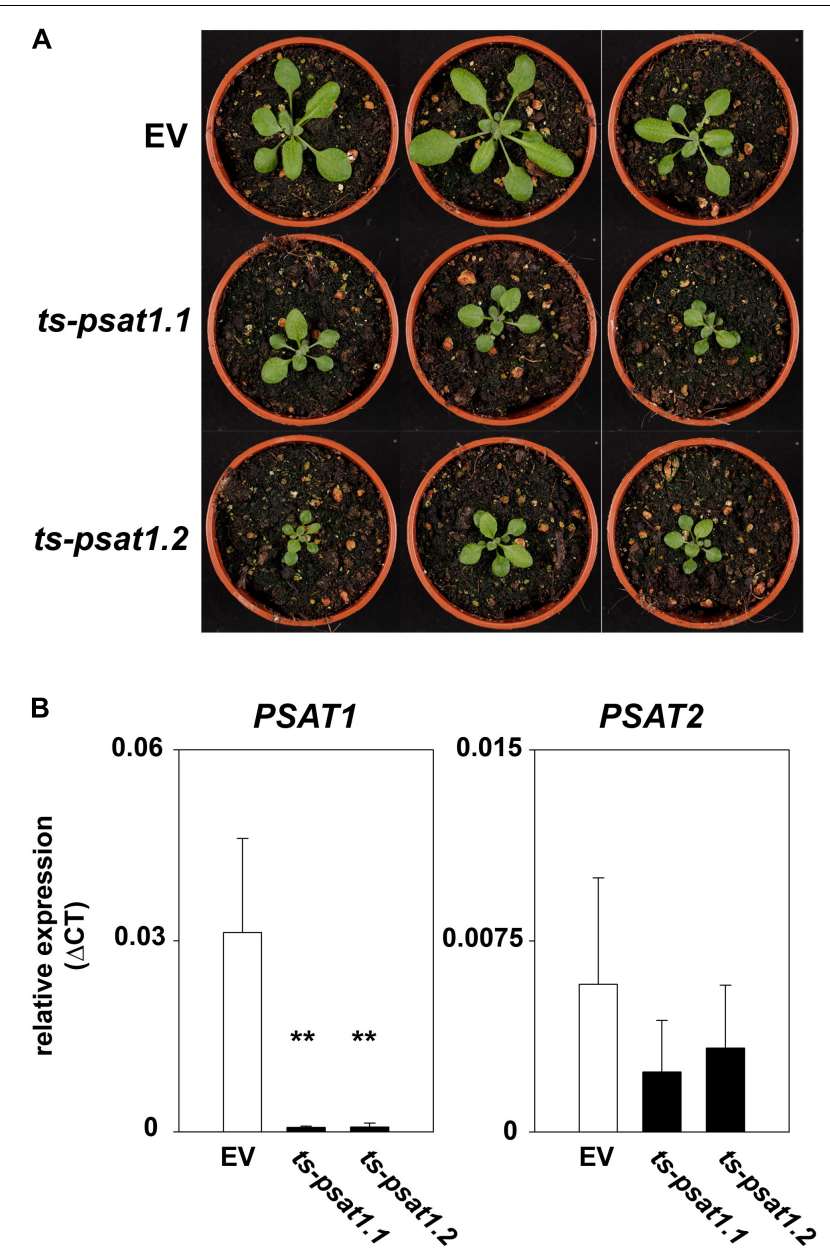

FIGURE 4 | Phenotype of PSAT1-silenced plants. (A) Shoot phenotype of the two independent PSAT1-silenced plant lines ts-psat1.1 and ts-psat1.2 under standard growth conditions (day/night $16 / 8 \mathrm{~h}, 100 \mu \mathrm{mol}_{\text {(photons) }} \mathrm{m}^{-2} \mathrm{~s}^{-1}$ ) in comparison to the empty vector (EV) control plants. (B) Relative expression of PSAT1 and PSAT2 genes in ts-psat1.1 and ts-psat1.2 plants in comparison to EV control plants. The values represent the mean of four independent measurements. Error bars indicate the SD. ${ }^{* *} P \leq 0.01$, indicate significant differences between PSAT1-silenced lines and EV control.

other amino acids, such as glutamine, arginine, aspartate, and asparagine was substantially increased in shoot and root tissue of these lines, whereas the content of lysine, threonine and valine was higher only in shoot tissue whereby the content of glutamate, glycine, alanine and phenylalanine was increased only in root tissue.

Altogether, these findings indicate that PSAT function is not only restricted to serine biosynthesis in plants.

\section{The PPSB Is Essential for Light and Sugar-Dependent Growth Promotion in Arabidopsis thaliana}

Plant growth is intimately associated with the ability to convert light into biochemical energy to assimilate $\mathrm{CO}_{2}$ for the production of biomass. Increasing light intensity in a 


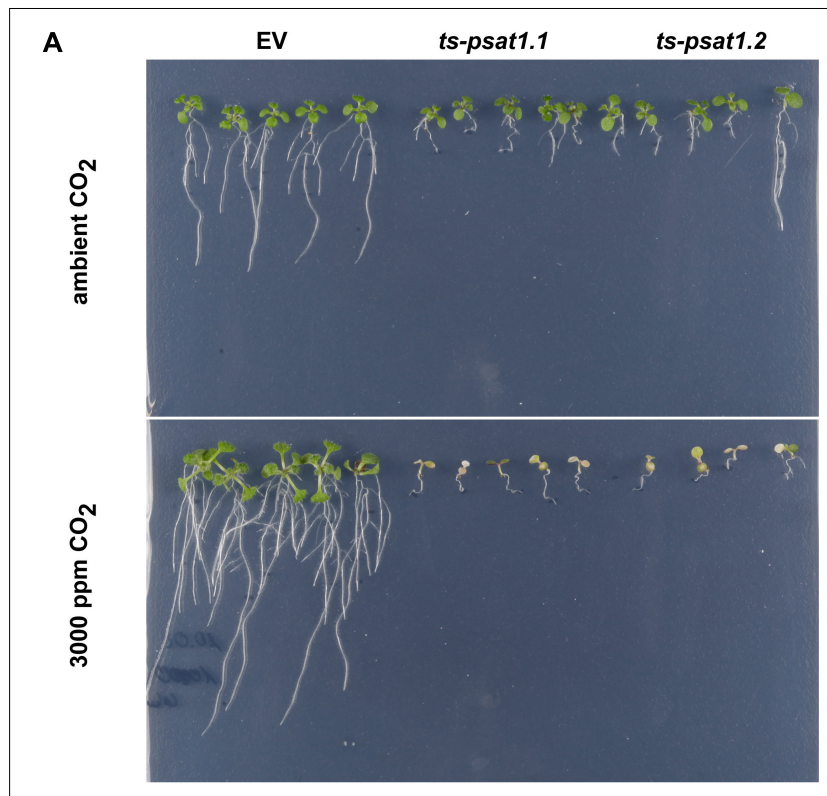

B

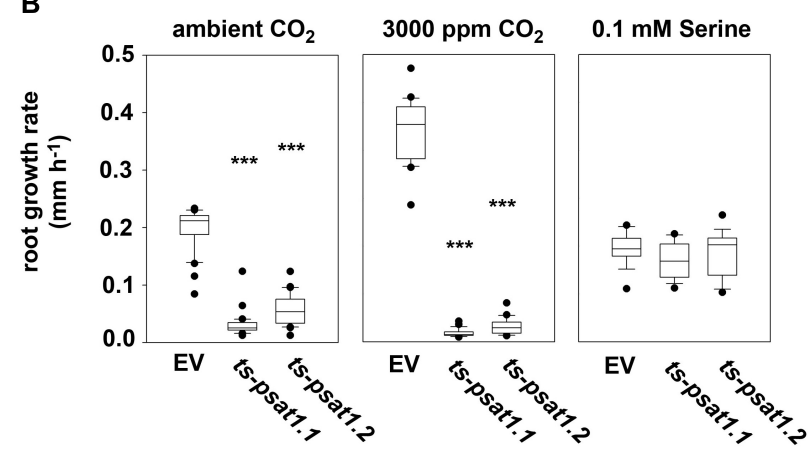

FIGURE 5 | PSAT1 is essential for plant growth at elevated $\mathrm{CO}_{2}$. (A) Growth phenotype of ts-psat1.1 and ts-psat1.2 lines at ambient (380 ppm) and elevated (3000 ppm) $\mathrm{CO}_{2}$. (B) The root growth rate $\left(\mathrm{mm} \mathrm{h}^{-1}\right)$ of ts-psat1.1 and ts-psat1.2 plant lines in comparison with empty vector (EV) control lines is shown. The root growth rate of plants grown at ambient $\mathrm{CO}_{2}$ (left), elevated $\mathrm{CO}_{2}$ (middle) and in the presence of $0.1 \mathrm{mM}$ serine (right) was determined daily. Therefore, 9 days old seedlings were transferred from ambient $\mathrm{CO}_{2}$ to elevated $\mathrm{CO}_{2}$ for 8 days. In parallel 6 days old seedlings were transferred from horizontal plates to vertical plates supplemented with $0.1 \mathrm{mM}$ serine and the root growth rate was determined every day for 11 days. ${ }^{* * *} P \leq 0.001$ indicate significant differences between PSAT1-silenced lines and EV control.

physiological range, results in enhanced biomass production as photosynthesis runs more efficiently. In addition, serine biosynthesis in plants is closely linked with photorespiration and therefore with photosynthesis. To test whether elevated photosynthesis can improve growth of PPSB-deficient plants, the leaf area of PSAT1 and PGDH1-silenced lines grown at $60 \mu \mathrm{mol}$ $\mathrm{m}^{-2} \mathrm{~s}^{-1}$ (low-light) and $180 \mu \mathrm{mol} \mathrm{m} \mathrm{m}^{-2} \mathrm{~s}^{-1}$ (high-light) was determined as a measure of growth analyzed and compared with the respective control plants (Figure 7A). The leaf area was determined of plants 7 and 14 days after germination.

At low-light conditions growth of PPSB-deficient lines was slightly reduced compared to control plants, but the differences were not significant for all analyzed lines. The increase in growth after additional 7 days was generally low at low light conditions. However, 14 days after germination growth of PPSBdeficient lines was significantly lower than growth of the control plants. This effect was much more pronounced when the plants were cultivated at high-light conditions. Already at 7 days after germination all PPSB-deficient lines were significantly smaller than the control plants and this effect increased substantially after additional 7 days. To further investigate the importance of the PPSB for the light-dependent plant growth promotion, we analyzed the expression of PPSB genes under low and highlight conditions. The expression of PGDH1 and PSAT1 was significantly elevated in plants grown under high-light conditions (Figure 8). These results are supported by publicly available expression data, showing a positive correlation between light intensity and PPSB gene expression (Supplementary Figure 2).

Growth promotion due to increased light intensity is directly associated with elevated photosynthesis and the result of raised synthesis of carbohydrates and their enhanced availability as energy and carbon source for biomass production (Slattery et al., 2018). Therefore, we tested the effect of carbohydrate feeding on growth promotion of PPSB-deficient lines and control plants (Figure 7B). To avoid strong influences of the light conditions, the carbohydrate feeding experiments were conducted under low-light. Under these conditions, growth of control plants on plates supplemented with $1.5 \%$ sucrose was significantly higher than of plants grown without external sugar. In contrast, sucroseinduced growth promotion could not be observed in PPSBdeficient plants. The importance of the PPSB for sugar-dependent growth promotion is further supported by the induced expression of PPSB genes after transfer of the plant to sugar-containing plates (Supplementary Figure 3).

Altogether, our data indicate that the biosynthesis of serine by the phosphorylated pathway is rate limiting for plant growth.

\section{Amino Acids and Starch Accumulate Under High-Light Condition in Shoots of PPSB-Deficient Plants}

The analysis of amino acid contents in plants showed a substantial increase in glycine, serine, histidine, alanine, valine, tryptophan, isoleucine, leucine, tyrosine, and glutamine in control plants grown under high-light conditions compared to plants grown under low-light conditions (Figure 9), whereas the contents of the other amino acids was not altered in these plants. In PPSB-deficient plants most of the amino acids, such as serine, histidine, valine, leucine, alanine, asparagine, threonine, isoleucine, lysine, glutamate, arginine, and glutamine accumulated stronger under low-light conditions than in control plants, but only for arginine, valine, asparagine, histidine, serine and glutamine the alteration was significant for both, PGDH1 and PSAT1-silenced lines. In most cases, except for leucine and lysine, the amino acid content in PPSB-deficient plants became significantly higher than in control plants under high-light conditions only.

In plants grown under elevated light conditions the carbon assimilation and therefore also the synthesis of starch is enhanced 


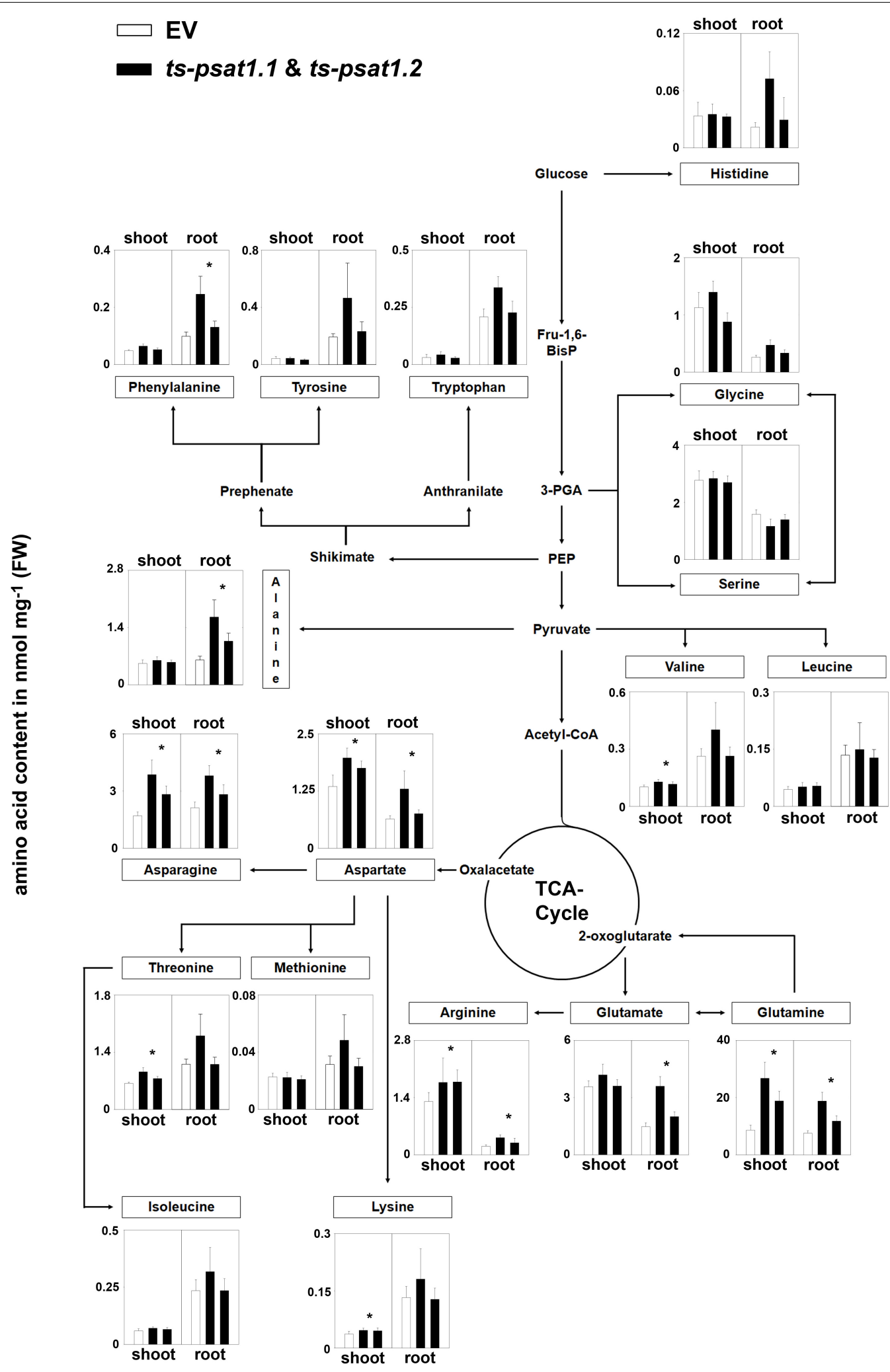

FIGURE 6 | Metabolic analysis of PSAT1-silenced lines. The amino acid content in shoot and root tissue of PSAT1-silenced lines (ts-psat1.1, ts-psat1.2) and empty vector (EV) transformed control plants are shown. The values represent the mean of four independent biological replicates. Error bars indicate the $S D$. $P \leq 0.05$, indicate significant differences between PSAT1-silenced lines and EV control. 


\section{A}

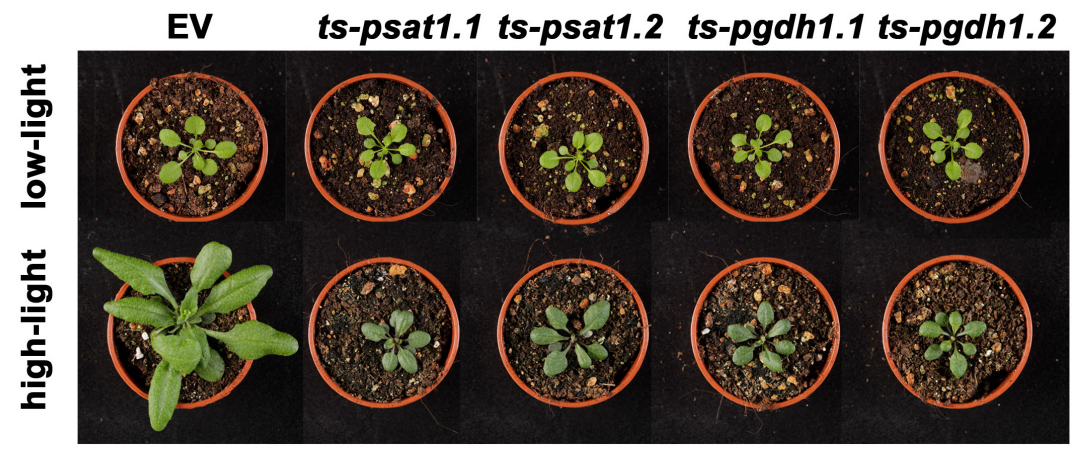

low-light

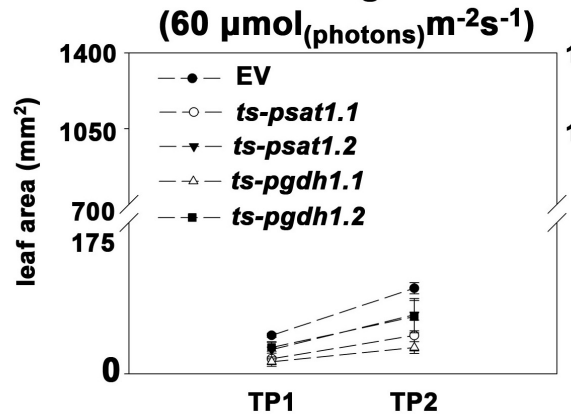

high-light

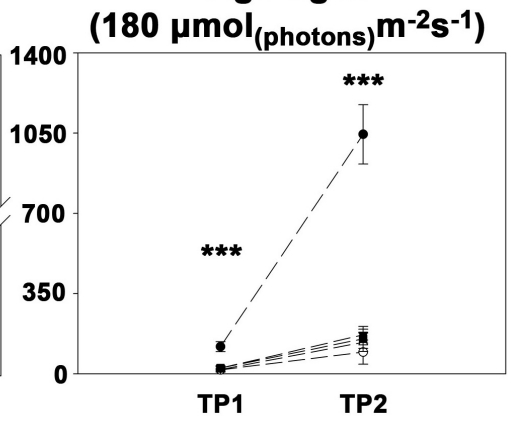

B

EV ts-psat1.1 ts-psat1.2 ts-pgdh1.1 ts-pgdh1.2

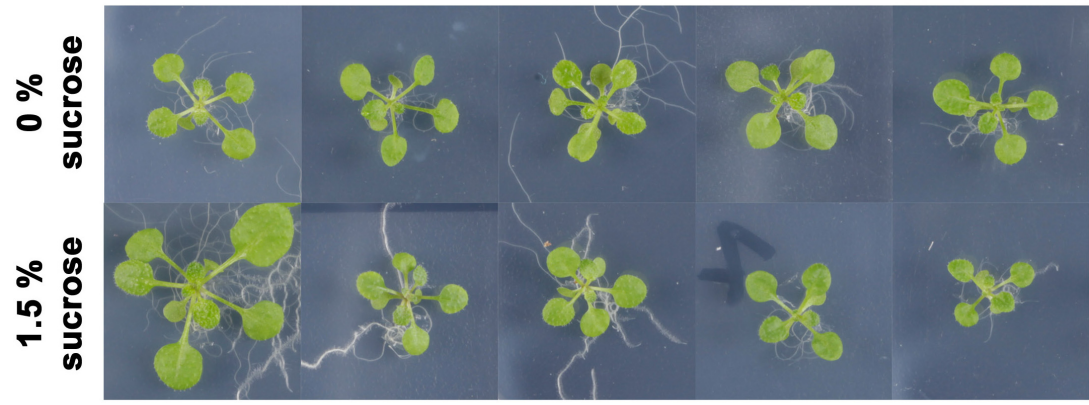

\section{EV}

ts-psat1.1
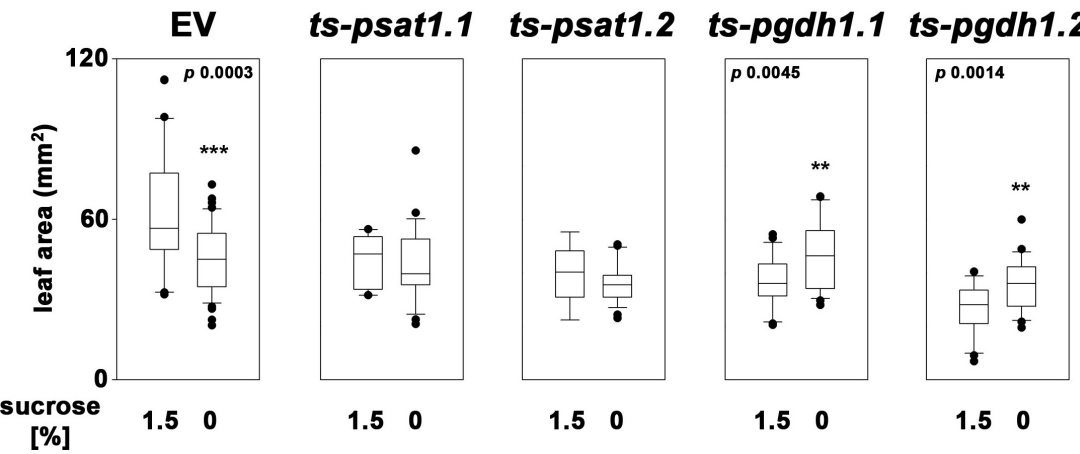

FIGURE 7 | The PPSB is essential for light and sugar-dependent growth promotion. (A) The leaf area was determined of empty vector (EV), PSAT1-silenced (ts-psat1.1, ts-psat1.2) and PGDH1-silenced (ts-pgdh1.1, ts-pgdh1.2) plants grown at low (60 $\mu$ mol (photons) $\mathrm{m}^{-2} \mathrm{~s}^{-1}$ ) and high (180 $\mu \mathrm{mol}$ (photons) $\left.\mathrm{m}^{-2} \mathrm{~s}^{-1}\right)$ light conditions. The leaf area was analyzed at two time points, 7 days after germination (TP1) and 14 days after germination (TP2). ${ }^{* * *} P \leq 0.001$, significant differences between PSAT1 - or PGDH1-silenced lines and the EV control. (B) The effect of externally applied sucrose on plant growth was studied in EV, PSAT1-silenced and $P G D H 1$-silenced plants. Plants were grown on $1 / 2 \mathrm{MS}$ medium with or without supplementation of $1.5 \%$ sucrose and growth promotion was determined by measuring the leaf area. ${ }^{* * *} P \leq 0.001,{ }^{* *} P \leq 0.01$, and ${ }^{*} P \leq 0.05$ indicate significant differences in leaf area between plants grown in the presence of $1.5 \%$ sucrose and plants grown on medium without sucrose. 


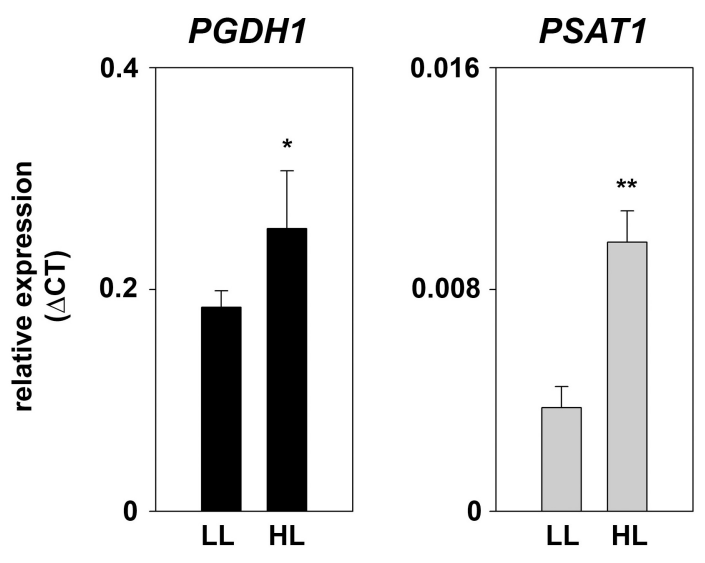

FIGURE 8 | Expression of PPSB genes at different light conditions. Expression of $P G D H 1$ and PSAT1 genes in plants grown at low-light (LL; $60 \mu \mathrm{mol}$ (photons) $\mathrm{m}^{-2} \mathrm{~s}^{-1}$ ) and high-light ( $\mathrm{HL} ; 180 \mu \mathrm{mol}$ (photons) $\mathrm{m}^{-2} \mathrm{~s}^{-1}$ ) conditions. Bars represent the mean of three biological replicates and error bars indicate SD. Asterisks designate significant differences $\left({ }^{*} P \leq 0.05\right.$; ${ }^{* *} P \leq 0.01$ ) between $\mathrm{LL}$ and $\mathrm{HL}$ treatment.

(Schmitz et al., 2014). Starch is a major carbon and energy storage in plants and positively correlates with plant growth (Sulpice et al., 2009). The analysis of the starch content revealed no significant difference between control and PPSB-deficient plants when grown under low-light conditions (Figure 9). Plants grown under high-light conditions accumulated significantly more starch, compared to those grown under low-light. In addition, the starch content was significantly higher in PPSBdeficient lines in comparison to control plants.

\section{DISCUSSION}

\section{The Arabidopsis Genome Possesses Two Genes Encoding for PSAT Enzymes}

The presence of PSAT activity in plants has been described previously by several studies (Larsson and Albertsson, 1979; Reynolds et al., 1988) and the gene encoding for the PSAT enzyme has been cloned from spinach and Arabidopsis (Saito et al., 1997; Ho et al., 1998). However, recent advances in genome sequencing revealed that two PSAT isoenzymes, namely PSAT1 (At4g35630) and PSAT2 (At2g17630) are encoded within the Arabidopsis genome ${ }^{5}$ and both enzymes have a high similarity with known PSAT enzymes of other species (Figure 2). Database search revealed that several plant species contain more than only one gene encoding for a PSAT enzyme (Supplementary Figure 1), indicating that the presence of multiple PSAT isoforms is common for plants.

The Arabidopsis PSAT isoforms, PSAT1 and PSAT2, contain an N-terminal sequence with a very high consensus score for a putative target peptide ${ }^{6}$, suggesting that both enzymes are functional within plastids. This is supported by the finding of $\mathrm{Ho}$

${ }^{5}$ https://www.arabidopsis.org/

${ }^{6} \mathrm{http}: / /$ aramemnon.uni-koeln.de et al. (1998), who showed that the target peptide of PSAT1 is able to guide GFP into plastids of Arabidopsis plants. These findings are in line with the plastidial localization of all other PPSB genes (Ho et al., 1998, 1999a,b; Benstein et al., 2013; Cascales-Minana et al., 2013). Thus, the whole sequence of the PPSB, including the PSAT reaction, is plastid localized.

\section{PSAT1 Represents the Major PSAT Isoform in Arabidopsis thaliana}

Expression analysis revealed that the PSAT1 gene is much higher expressed in shoot and root tissue of Arabidopsis than the PSAT2 gene (Figure 3). The expression of PSAT1 is high in the vasculature of leaves, the shoot apical meristem, the vasculature of the root and the root apical meristem. This expression pattern is very similar to the expression of PGDH1, the main PGDH isoform (Benstein et al., 2013; Toujani et al., 2013), suggesting that PSAT1 could be the main PSAT enzyme in Arabidopsis.

To test whether PSAT1 plays an important role in Arabidopsis, PSAT1-silenced lines (ts-psat1.1 and ts-psat1.2) were generated. In these plants, the expression of PSAT1 is strongly reduced, whereas expression of PSAT2 is not significantly altered (Figure 4). Therefore, the strong growth phenotype of the silenced lines (Figure 4) can be attributed to the specific down regulation of the PSAT1 expression and the loss of PSAT1 activity cannot be compensated by PSAT2.

Previous studies on the function of the PPSB showed that PGDH1 represents the major isoform as knockout mutants of this gene are embryo-lethal and silencing lines are retarded in growth (Benstein et al., 2013). In contrast, PGDH2 knock out mutants are viable and showed no obvious phenotype (Benstein et al., 2013; Toujani et al., 2013). Therefore, it is very likely that PSAT1 represents the main PSAT enzyme in Arabidopsis, whereas the PSAT2 enzyme might have a subordinate function only.

The growth phenotype of PSAT1-silenced plants is enhanced when growing plants under non-photorespiratory elevated $\mathrm{CO}_{2}$ conditions and can be rescued by growing the plants on medium supplemented with serine (Figure 5). This phenotype is very similar to the appearance of plants with reduced PGDH1 and PSP activity (Benstein et al., 2013; Cascales-Minana et al., 2013). Increasing the $\mathrm{CO}_{2}$ concentration has been shown to be an efficient method to inhibit the photorespiration as under these conditions the RuBisCO enzymes prefers the carboxylation reaction (Eisenhut et al., 2013). Therefore, the higher sensitivity of PGDH1 and also PSAT1-silenced plants against elevated $\mathrm{CO}_{2}$ can be explained by the simultaneous inhibition of the photorespiratory and PPSB-mediated serine biosynthesis.

The co-existence of several pathways for serine biosynthesis suggests, that one pathway alone is insufficient in fulfilling the demand for serine in plants. The enhanced expression of PGDH1 (Benstein et al., 2013) as well as PSAT1 (Figure 3) in heterotrophic and inter alia in meristematic tissue suggests a function of the PPSB in serine provision in cells, which are only insufficiently supplied with serine produced by photorespiration. In proliferating cells of the meristem, the rate of nucleic acid synthesis is high and consequently, also the demand for nucleotides and S-adenosylmethionine (Douce et al., 2001; Jabrin 


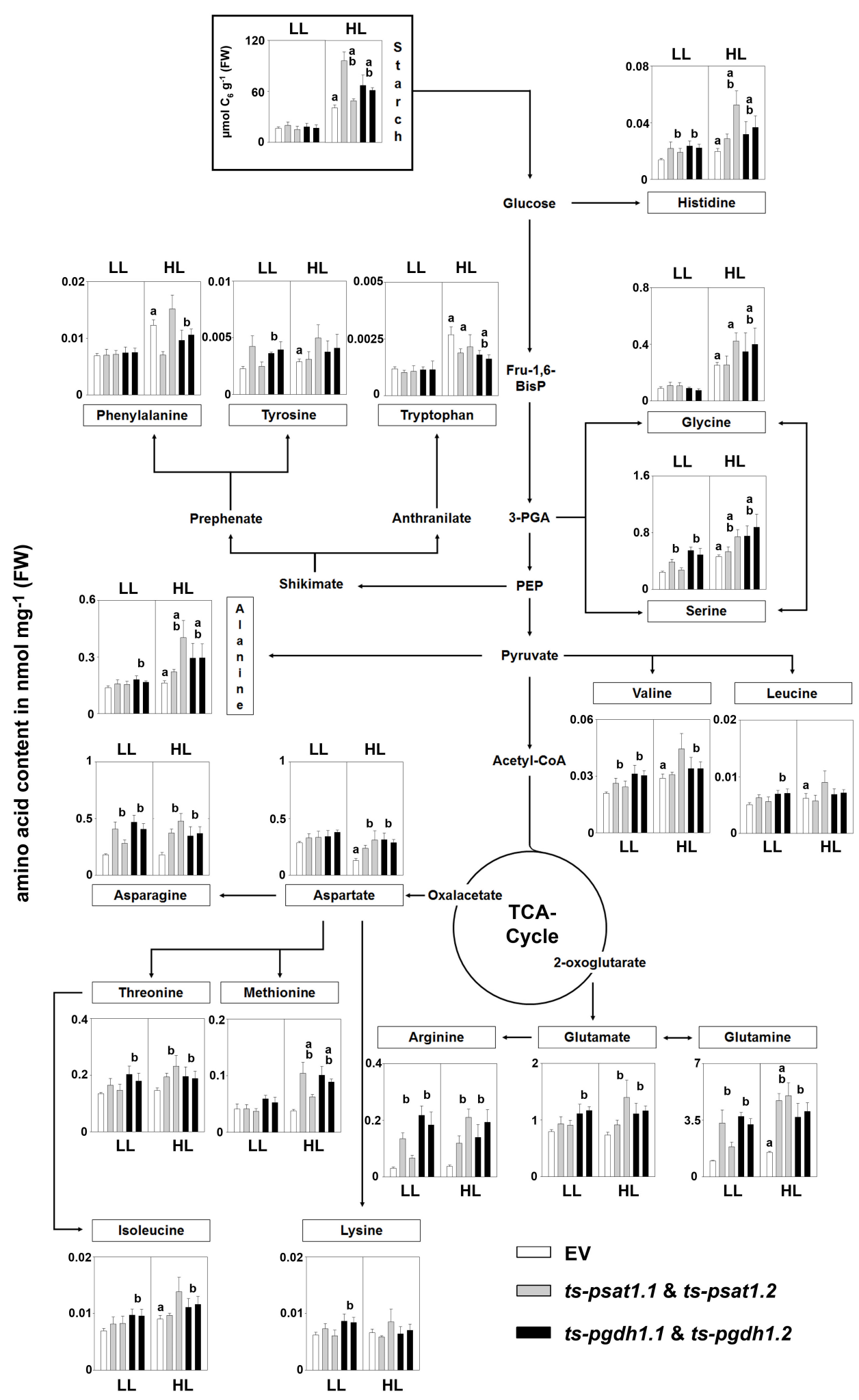

FIGURE 9 | Metabolic analysis of PSAT1 and PGDH1-silenced lines grown under low- and high-light conditions. The amino acid content in shoot tissue of PSAT1-silenced lines (ts-psat1.1, ts-psat1.2), PGDH1-silenced lines (ts-pgdh1.1, ts-pgdh1.2) and empty vector (EV) transformed control plants grown at low-light $\left(60 \mu \mathrm{mol}\right.$ (photons) $\left.\mathrm{m}^{-2} \mathrm{~s}^{-1}\right)$ or high-light $\left(180 \mu \mathrm{mol}\right.$ (photons) $\left.\mathrm{m}^{-2} \mathrm{~s}^{-1}\right)$ conditions are shown. The values represent the mean of four independent biological replicates. Error bars indicate the SD. a, indicate significant differences $(P \leq 0.05)$ between high-light and low-light grown plants and b, indicate significant differences $(P \leq 0.05)$ between PSAT1 or PGDH1-silenced lines and the EV control plants. 
et al., 2003; Sahr et al., 2005). Thus, serine synthesized by the PPSB might be important to provide one-carbon units for the tetrahydrofolate metabolism and therefore for the synthesis of S-adenosylmethionine, purine and pyrimidine bases in these cells.

According to the metabolite analysis, the content of serine was unaltered in PSAT1-silenced plants (Figure 6), similarly, to previous observations for $P G D H 1$-silenced lines or conditional psp1 mutant plants (Benstein et al., 2013; Cascales-Minana et al., 2013). However, the growth phenotype of the silenced plants can be rescued by external application of serine, indicating that serine deficiency is the major issue these plants have. Therefore, the majority of serine measured in PSAT1-silenced plants is most likely synthesized via photorespiration, whereas serine synthesized by the PPSB might be restricted to few cells only and account for a comparatively small part of the total serine content. Due to the resulting small impact on the total serine pool size, serine quantification on the whole plant level appears to be an inappropriate measure for PPSB-dependent serine synthesis.

The most obvious metabolic phenotype of PSAT1-silenced plants is the strong accumulation of glutamine and some other amino acids in shoot and root tissue (Figure 6). This phenotype is very similar to the phenotype observed for $P G D H 1$-silenced plants (Benstein et al., 2013) and might be the result of a disturbed ammonium assimilation in these plants. The PSAT reaction represents a putative link between PPSB activity and ammonium assimilation. The PSAT enzyme catalyzes the transfer of the amino group from glutamate to 3-phosphohydroxypyruvate, yielding in one molecule 3-phosphoserine and one molecule 2oxoglutarate. The 2-oxoglutarate released by the PSAT activity can be directly recycled into glutamate by the GOGAT enzyme in plastids. Deficiency in the PSAT activity might disturb this recycling mechanism, causing 2-oxoglutarate deficiency in plastids and subsequent accumulation of glutamine. To prevent accruing of toxic ammonium, plants possess additional pathways for ammonium assimilation by synthesizing aspartate, asparagine, and arginine (Potel et al., 2009). The elevated level of these amino acids supports our hypothesis, although other reasons for this phenotype cannot be excluded.

\section{The PPSB Is Essential for Light and Sugar-Dependent Plant Growth Promotion}

Plant growth and development is intimately associated with the quantity of light. Under optimal growth conditions, e.g., water and nutrient availability, elevated light increases $\mathrm{CO}_{2}$ assimilation and consequently biomass production (Slattery et al., 2018). Interestingly, this effect is strongly impaired in PPSB-deficient plants (Figure 7). While growth of the control plants under elevated light conditions was massively increased compared to low-light conditions, growth of PGDH1 as well as PSAT1-silenced plants was not substantially improved by high-light. This effect cannot be attributed to a general serine deficiency in these plants, as under high-light conditions the total serine content was even higher in PGDH1 and
PSAT1-silenced lines than in the control plants (Figure 9). The higher serine content is most likely the consequence of an elevated photorespiration, which is supported by the fact that also the glycine content was markedly raised under these conditions. Photorespiration is tightly associated with ammonium assimilation in plants (Coschigano et al., 1998). Elevated flux through the photorespiratory pathway could also explain why the content of most other amino acids was increased in shoots of PPSB-deficient plants. However, the strong growth phenotype of the silenced lines under high-light conditions in turn leads to the question, why the higher serine content is insufficient for rescuing the phenotype of PPSB-deficient plants? These results can only be explained by considering the presence of independent pools of serine in plants, which are not efficiently connected to each other. The growth arrest of PPSB-deficient plants under non-photorespiratory elevated $\mathrm{CO}_{2}$ conditions clearly shows that both serine biosynthetic pathways are interconnected. However, it is very likely that serine transport out of mesophyll cells, where photorespiration takes place, into the cells of the meristems, where the PPSB is highly active, is limiting.

Similarly to the effect of elevated light, external application of sugar also promotes plant growth (Blasing et al., 2005; Eckstein et al., 2012). Cultivation of plants on medium supplemented with $1.5 \%$ sucrose substantially improved growth of control plants, but not of PPSB-deficient lines. These results are in line with the observation that PPSB-deficient plant accumulate significantly more starch under high-light conditions than control plants (Figure 9). Hence, PPSB-deficient plants are not able to convert the energy provided in form of carbohydrates into biomass. The importance of the PPSB for plant growth is further supported by the fact that the expression of PGDH1 and PSAT1 was significantly up-regulated by high-light and the application of carbohydrates (Figure 8 and Supplementary Figures 2, 3).

Altogether, our findings indicate that serine biosynthesis by the PPSB is rate limiting for plant growth.

\section{MATERIALS AND METHODS}

\section{Plant Material and Cultivation Conditions}

PSAT1-silenced lines (ts-psat1.1 and ts-psat1.2) were generated by fusion of a PSAT1 genomic fragment to the target site of the trans-acting small interfering RNA miR173 (Felippes et al., 2012). For this, a cDNA fragment of was amplified using a modified oligonucleotide that included the miR173 target sequence. The PCR amplicon was cloned into the pENTR/DTOPO (Invitrogen) vector and recombined into the pAM-PATGWPro35S vector (Jakoby et al., 2006). The generated construct was transformed into the Agrobacterium tumefaciens strain GV3101 pmp90RK and subsequently into Arabidopsis Col-0. Transformed plants were germinated on soil and transgenic lines were selected by spraying with glufosinate (BASTA).

PGDH1-silenced lines (ts-pgdh1.1 and ts-pgdh1.2) and the respective empty vector (EV) control plants were previously described by Benstein et al. (2013). 
Plants were either grown on half-strength Murashige and Skoog medium without sucrose or on soil. The plants were stratified at $4^{\circ} \mathrm{C}$ in darkness for 2.5 and 4 days, respectively, before transfer to a plant growth chamber $\left[22^{\circ} \mathrm{C}, 16 \mathrm{~h}\right.$ light, $100 \mu \mathrm{mol}$ (photon) $\mathrm{m}^{-2} \mathrm{~s}^{-1}$.

\section{Root Growth Analyses}

For determination of the primary root growth rate, seeds of silenced and control plants were germinated for 4 days after stratification on $1 / 2$ MS plates before transfer to vertical plates for additional 10 days of culture. To test whether external serine can rescue the root growth phenotype of PSAT1-silenced plants, seeds were germinated on $1 / 2$ MS medium supplemented with $100 \mu \mathrm{M}$ serine and later transferred to vertical plates supplemented with serine. The root growth was tracked over the whole growth period. For root growth measurement, images were taken using a standard digital camera (Nikon) and the evaluation of the pictures was performed by using the ImageJ software ${ }^{7}$.

\section{Expression Analysis by qRT-PCR}

For the analysis of gene transcripts, RNA was extracted from plant material by hot phenol extraction and subsequent $\mathrm{LiCl}$ precipitation. Extracted RNA samples were treated with a TURBO DNA-free kit (Ambion) and were subsequently used for cDNA synthesis via the Bioscript Reverse Transcription kit (Bioline). Quantification of gene expression was achieved by quantitative Real Time Polymerase Chain Reaction using the 7300 Real-Time PCR System and SYBR Green (Applied Biosystems). Ubiquitin and actin served as housekeeping genes.

\section{Histochemical Analysis of Promoter:GUS Construct Lines}

Plants expressing the $\beta$-glucuronidase (GUS) reporter gene under control of the native PSAT1 or PSAT2 promoter (ProPSAT1:GUS; ProPSAT2:GUS, Benstein et al., 2013) were cultivated for 10 days on $1 / 2$ MS plates. For histochemical staining of GUS activity, seedlings were vacuum infiltrated (Vacuubrand $\mathrm{GmbH}$ ) five times for $1 \mathrm{~min}$ in staining solution $\left[0.1 \mathrm{M} \mathrm{NaH}_{4} \mathrm{PO}_{4} \mathrm{pH}\right.$ 7.2, $10 \mathrm{mM}$ EDTA, $0.5 \mathrm{mM}$ K-ferrocyanide $\left(\mathrm{K}_{4} \mathrm{Fe}(\mathrm{CN})_{6}\right), 5 \mathrm{mM}$ K-ferricyanide $\left(\mathrm{K}_{3} \mathrm{Fe}(\mathrm{CN})_{6}\right), 0.1 \%$ Triton $\mathrm{X}-100$ and $20 \mathrm{mM}$ $\mathrm{X}$-Gluc/DMSO] and thereafter incubated at $37^{\circ} \mathrm{C}$ overnight. Subsequently, seedlings were destained with $70 \% \mathrm{EtOH}$ at $60^{\circ} \mathrm{C}$, again incubated in fresh $70 \% \mathrm{EtOH}$ and were then viewed under the binocular microscope (Leica S84PO) for GUS activity.

\footnotetext{
${ }^{7}$ https://imagej.nih.gov/ij/
}

\section{REFERENCES}

Achouri, Y., Rider, M. H., Schaftingen, E. V., and Robbi, M. (1997). Cloning, sequencing and expression of rat liver 3-phosphoglycerate dehydrogenase. Biochem. J. 323(Pt 2), 365-370. doi: 10.1042/bj3230365

\section{Extraction and Measurements of Metabolites}

For quantification of amino acids, lyophylized plant material was extracted with $80 \% \mathrm{ETOH}$ and the extract was diluted 1:10 with water. Twenty microliters of the diluted extract were injected into the HPLC before HPLC analysis. Amino acids were separated using a HyperClone 3u ODS (C18)120 $150 \times 4.6 \mathrm{~mm}$ column (Phenomenex) connected to the Dionex UltiMateTM 3000 system (Thermo Fisher Scientific). The HPLC system held a discontinuous flow gradient comprising solvent A $(8.8 \mathrm{mM}$ $\mathrm{NaPO} 4, \mathrm{pH} 7.5$, and $0.2 \%(\mathrm{v} / \mathrm{v})$ tetrahydrofuran) and increasing proportion of solvent B (18.7 mM NaPO4, pH 7.5, 32.7\% (v/v) $\mathrm{MeOH}$ and $20.6 \%(\mathrm{v} / \mathrm{v})$ acetonitrile), at a flow rate of $0.8 \mathrm{~mL} / \mathrm{min}$. Quantification was performed by pre-column derivatization with ortho-phtalaldehyde (OPA; Grace Davison Discovery Science) and subsequently quantified by fluorescence detection of the obtained derivatives according to Lindroth and Mopper (1979).

Starch was isolated from lyophylized plant material as described by Lin et al. (1988) and the content was determined with a coupled enzymatic assay as described earlier by Stitt (1989) using a Spectrafluor Plus plate reader (TECAN, Austria) in the absorbance mode.

\section{AUTHOR CONTRIBUTIONS}

SW and SK conducted the research and wrote the manuscript. SK designed the research.

\section{FUNDING}

The research of SK was supported by the University of Cologne, CEPLAS (DFG grant EXC1028) and the Deutsche Forschungsgemeinschaft (Grant Kr4245/1-1; Kr4245/2-1). The research of SW was supported by the University of Cologne.

\section{ACKNOWLEDGMENTS}

We acknowledge Diana Vogelmann for technical assistance and Rainer Schwacke (Research Centre, Jülich) for critical comments and discussion.

\section{SUPPLEMENTARY MATERIAL}

The Supplementary Material for this article can be found online at: https://www.frontiersin.org/articles/10.3389/fpls.2018.01712/ full\#supplementary-material

Benstein, R. M., Ludewig, K., Wulfert, S., Wittek, S., Gigolashvili, T., Frerigmann, H., et al. (2013). Arabidopsis phosphoglycerate dehydrogenasel of the phosphoserine pathway is essential for development and required for ammonium assimilation and tryptophan biosynthesis. Plant Cell 25, 50115029. doi: 10.1105/tpc.113.118992 
Blasing, O. E., Gibon, Y., Gunther, M., Hohne, M., Morcuende, R., Osuna, D., et al. (2005). Sugars and circadian regulation make major contributions to the global regulation of diurnal gene expression in Arabidopsis. Plant Cell 17, 3257-3281. doi: 10.1105/tpc.105.035261

Busch, F. A., Sage, R. F., and Farquhar, G. D. (2018). Plants increase CO2 uptake by assimilating nitrogen via the photorespiratory pathway. Nat. Plants 4, 46-54. doi: 10.1038/s41477-017-0065-x

Cascales-Minana, B., Munoz-Bertomeu, J., Flores-Tornero, M., Anoman, A. D., Pertusa, J., Alaiz, M., et al. (2013). The phosphorylated pathway of serine biosynthesis is essential both for male gametophyte and embryo development and for root growth in Arabidopsis. Plant Cell 25, 2084-2101. doi: 10.1105/tpc. 113.112359

Coschigano, K. T., Melo-Oliveira, R., Lim, J., and Coruzzi, G. M. (1998). Arabidopsis gls mutants and distinct Fd-GOGAT genes. Implications for photorespiration and primary nitrogen assimilation. Plant Cell 10, 741-752. doi: $10.2307 / 3870661$

Dey, S., Hu, Z., Xu, X. L., Sacchettini, J. C., and Grant, G. A. (2005). D-3Phosphoglycerate dehydrogenase from Mycobacterium tuberculosis is a link between the Escherichia coli and mammalian enzymes. J. Biol. Chem. 280, 14884-14891. doi: 10.1074/jbc.M414488200

Douce, R., Bourguignon, J., Neuburger, M., and Rebeille, F. (2001). The glycine decarboxylase system: a fascinating complex. Trends Plant Sci. 6, 167-176. doi: 10.1016/S1360-1385(01)01892-1

Eckstein, A., Ziêba, P., and Gabryś, H. (2012). Sugar and light effects on the condition of the photosynthetic apparatus of Arabidopsis thaliana cultured in vitro. J. Plant Growth Regulation 31, 90-101. doi: 10.1007/s00344-0119222-z

Eisenhut, M., Planchais, S., Cabassa, C., Guivarc'h, A., Justin, A. M., Taconnat, L., et al. (2013). Arabidopsis A BOUT DE SOUFFLE is a putative mitochondrial transporter involved in photorespiratory metabolism and is required for meristem growth at ambient $\mathrm{CO}(2)$ levels. Plant J. 73, 836-849. doi: 10.1111/ tpj. 12082

Felippes, F. F., Wang, J. W., and Weigel, D. (2012). MIGS: miRNAinduced gene silencing. Plant J. 70, 541-547. doi: 10.1111/j.1365-313X.2011. 04896.x

Hirayama, C., Saito, H., Konno, K., and Shinbo, H. (1998). Purification and characterization of NADH-dependent glutamate synthase from the silkworm fat body (Bombyx mori). Insect Biochem. Mol. Biol. 28, 473-482. doi: 10.1016/ S0965-1748(98)00019-8

Ho, C. L., Noji, M., and Saito, K. (1999a). Plastidic pathway of serine biosynthesis. Molecular cloning and expression of 3-phosphoserine phosphatase from Arabidopsis thaliana. J. Biol. Chem. 274, 11007-11012.

Ho, C. L., Noji, M., Saito, M., and Saito, K. (1999b). Regulation of serine biosynthesis in Arabidopsis. Crucial role of plastidic 3-phosphoglycerate dehydrogenase in non-photosynthetic tissues. J. Biol. Chem. 274, 397-402.

Ho, C. L., Noji, M., Saito, M., Yamazaki, M., and Saito, K. (1998). Molecular characterization of plastidic phosphoserine aminotransferase in serine biosynthesis from Arabidopsis. Plant J. 16, 443-452. doi: 10.1046/j.1365313x.1998.00313.x

Ho, C. L., and Saito, K. (2001). Molecular biology of the plastidic phosphorylated serine biosynthetic pathway in Arabidopsis thaliana. Amino Acids 20, 243-259. doi: $10.1007 /$ s007260170042

Jabrin, S., Ravanel, S., Gambonnet, B., Douce, R., and Rebeille, F. (2003). Onecarbon metabolism in plants. Regulation of tetrahydrofolate synthesis during germination and seedling development. Plant Physiol. 131, 1431-1439. doi: 10.1104/pp.016915

Jakoby, M. J., Weinl, C., Pusch, S., Kuijt, S. J., Merkle, T., Dissmeyer, N., et al. (2006). Analysis of the subcellular localization, function, and proteolytic control of the Arabidopsis cyclin-dependent kinase inhibitor ICK1/KRP1. Plant Physiol. 141, 1293-1305. doi: 10.1104/pp.106.081406

Kleczkowski, L. A., and Givan, C. V. (1988). Serine formation in leaves by mechanisms other than the glycolate pathway. J. Plant Physiol. 132, 641-652. doi: 10.1016/S0176-1617(88)80223-2

Krueger, S., Niehl, A., Lopez Martin, M. C., Steinhauser, D., Donath, A., Hildebrandt, T., et al. (2009). Analysis of cytosolic and plastidic serine acetyltransferase mutants and subcellular metabolite distributions suggests interplay of the cellular compartments for cysteine biosynthesis in Arabidopsis. Plant Cell Environ. 32, 349-367. doi: 10.1111/j.1365-3040.2008.01928.x
Larsson, C., and Albertsson, E. (1979). Enzymes related to serine biosynthesis in spinach chloroplasts. Physiol. Plant. 45, 7-10. doi: 10.1111/j.1399-3054.1979. tb01654.x

Lin, T. P., Caspar, T., Somerville, C., and Preiss, J. (1988). Isolation and Characterization of a starchless mutant of Arabidopsis thaliana (L.) heynh lacking ADPglucose pyrophosphorylase activity. Plant Physiol. 86, 1131-1135. doi: $10.1104 / \mathrm{pp} .86 .4 .1131$

Lindroth, P., and Mopper, K. (1979). High performance liquid chromatographic determination of subpicomole amounts of amino acids by precolumn fluorescence derivatization with o-phthaldialdehyde. Anal. Chem. 51, 16671674. doi: 10.1021/ac50047a019

Mehta, P. K., Hale, T. I., and Christen, P. (1993). Aminotransferases: demonstration of homology and division into evolutionary subgroups. Eur. J. Biochem. 214, 549-561. doi: 10.1111/j.1432-1033.1993.tb17953.x

Melcher, K., and Entian, K. D. (1992). Genetic analysis of serine biosynthesis and glucose repression in yeast. Curr. Genet. 21, 295-300. doi: 10.1007/ BF00351686

Modde, K., Timm, S., Florian, A., Michl, K., Fernie, A. R., and Bauwe, H. (2017). High serine:glyoxylate aminotransferase activity lowers leaf daytime serine levels, inducing the phosphoserine pathway in Arabidopsis. J. Exp. Bot. 68, 643-656. doi: 10.1093/jxb/erw467

Pizer, L. I. (1963). The pathway and control of serine biosynthesis in Escherichia coli. J. Biol. Chem. 238, 3934-3944.

Potel, F., Valadier, M. H., Ferrario-Mery, S., Grandjean, O., Morin, H., Gaufichon, L., et al. (2009). Assimilation of excess ammonium into amino acids and nitrogen translocation in Arabidopsis thaliana-roles of glutamate synthases and carbamoylphosphate synthetase in leaves. FEBS J. 276, 4061-4076. doi: 10.1111/j.1742-4658.2009.07114.x

Rebeille, F., Alban, C., Bourguignon, J., Ravanel, S., and Douce, R. (2007). The role of plant mitochondria in the biosynthesis of coenzymes. Photosynth. Res. 92, 149-162. doi: 10.1007/s11120-007-9167-z

Reynolds, P. H. S., Hine, A., and Rodber, K. (1988). Serine metabolism in legume nodules: purification and properties of phosphoserine aminotransferase. Physiol. Plant. 74, 194-199. doi: 10.1111/j.1399-3054.1988. tb04963.x

Ros, R., Munoz-Bertomeu, J., and Krueger, S. (2014). Serine in plants: biosynthesis, metabolism, and functions. Trends Plant Sci. 19, 564-569. doi: 10.1016/j.tplants. 2014.06.003

Sahr, T., Ravanel, S., and Rebeille, F. (2005). Tetrahydrofolate biosynthesis and distribution in higher plants. Biochem. Soc. Trans. 33, 758-762. doi: 10.1042/ BST0330758

Saito, K., Takagi, Y., Ling, H. C., Takahashi, H., and Noji, M. (1997). Molecular cloning, characterization and expression of cDNA encoding phosphoserine aminotransferase involved in phosphorylated pathway of serine biosynthesis from spinach. Plant Mol. Biol. 33, 359-366. doi: 10.1023/A:1005730725764

Schmitz, J., Heinrichs, L., Scossa, F., Fernie, A. R., Oelze, M. L., Dietz, K. J., et al. (2014). The essential role of sugar metabolism in the acclimation response of Arabidopsis thaliana to high light intensities. J. Exp. Bot. 65, 1619-1636. doi: 10.1093/jxb/eru027

Schwacke, R., Schneider, A., Van Der Graaff, E., Fischer, K., Catoni, E., Desimone, M., et al. (2003). ARAMEMNON, a novel database for Arabidopsis integral membrane proteins. Plant Physiol. 131, 16-26. doi: 10.1104/pp.011577

Slattery, R. A., Walker, B. J., Weber, A. P. M., and Ort, D. R. (2018). The impacts of fluctuating light on crop performance. Plant Physiol. 176, 990-1003. doi: 10.1104/pp.17.01234

Snell, K. (1984). Enzymes of serine metabolism in normal, developing and neoplastic rat tissues. Adv. Enzyme Regul. 22, 325-400. doi: 10.1016/00652571(84)90021-9

Stitt, M. (1989). Product inhibition of potato tuber pyrophosphate:fructose-6phosphate phosphotransferase by phosphate and pyrophosphate. Plant Physiol. 89, 628-633. doi: 10.1104/pp.89.2.628

Sulpice, R., Pyl, E. T., Ishihara, H., Trenkamp, S., Steinfath, M., Witucka-Wall, H., et al. (2009). Starch as a major integrator in the regulation of plant growth. Proc. Natl. Acad. Sci. U.S.A. 106, 10348-10353. doi: 10.1073/pnas.0903478106

Toujani, W., Munoz-Bertomeu, J., Flores-Tornero, M., Rosa-Tellez, S., Anoman, A. D., Alseekh, S., et al. (2013). Functional characterization of the plastidial 3-phosphoglycerate dehydrogenase family in Arabidopsis. Plant Physiol. 163, 1164-1178. doi: 10.1104/pp.113.226720 
Tzin, V., and Galili, G. (2010). The biosynthetic pathways for shikimate and aromatic amino acids in Arabidopsis thaliana. Arabidopsis Book 8:e0132. doi: $10.1199 /$ tab.0132

Vance, J. E., and Steenbergen, R. (2005). Metabolism and functions of phosphatidylserine. Prog. Lipid Res. 44, 207-234. doi: 10.1016/j.plipres.2005. 05.001

Zhang, Q., Lee, J., Pandurangan, S., Clarke, M., Pajak, A., and Marsolais, F. (2013). Characterization of Arabidopsis serine:glyoxylate aminotransferase, AGT1, as an asparagine aminotransferase. Phytochemistry 85, 30-35. doi: 10. 1016/j.phytochem.2012.09.017
Conflict of Interest Statement: The authors declare that the research was conducted in the absence of any commercial or financial relationships that could be construed as a potential conflict of interest.

Copyright () 2018 Wulfert and Krueger. This is an open-access article distributed under the terms of the Creative Commons Attribution License (CC BY). The use, distribution or reproduction in other forums is permitted, provided the original author(s) and the copyright owner(s) are credited and that the original publication in this journal is cited, in accordance with accepted academic practice. No use, distribution or reproduction is permitted which does not comply with these terms. 